\title{
The Effects of Students' Cognition of Their College and Department's Core Competencies and Collective-efficacy on Satisfaction and GPA
}

\author{
Hoe-Chang Yang \\ Dept. of Distribution Management, Jangan University \\ pricezzang@jangan.ac.kr
}

\begin{abstract}
This study aims to find factors to improve students' major satisfaction and GPA, from the perspective of person-organization fit in order to deal with the government's pressure on restructuring and reinforce the competitiveness of colleges. The results showed that core competencies and collective efficacy respectively improved self-efficacy and self-esteem, and college major's core competencies, collective efficacy and self-efficacy positively influenced major satisfaction.
\end{abstract}

Keywords: Core competence, Collective efficacy, Self-efficacy, Self-esteem, Satisfaction, $G P A$.

\section{Introduction}

Korean community colleges are currently facing pressure of severe change. Korean colleges have achieved qualitative development, but Korean education has not reached quantitative development yet. It has been pointed out that several colleges located in country sides established after permissive system are insecure colleges and do not coincide with educational purpose. Also, it has been viewed that reduction of number of college subject students will take place and colleges have entered unlimited competition and it is expected that this competition will be intensified [1]. This study starts from the consideration of how community colleges should correspond to this change and gain competitiveness. Not only companies, but also colleges must obtain competitive advantage which is the core of success and failure. According to [2]'s assertion, college management should effectively input possessed resources to create profit and fulfill the goal of the organization. On one side, innovation should be demanded from members to actualize excess profit compared with competitive schools and must have the role of developing sound school culture. In this aspect, competition strategy of community colleges is decision making to maintain continuous competitive advantage within national colleges and promoting investment, effective distribution of resources. This is deciding the direction community colleges pursue in the future, make efficient organizations, and effectively distributing human resources and tangible, intangible resources associated to the college [2].

Article history:

Received (September 03, 2016), Review Result (November 27, 2016), Accepted (December 21, 2016) 


\section{Related researches}

RBV (Resource-based View) changes the aspect of research subjects from industry and environment to within the company and asserts that significance of interior resources and resources can be applied in results (e.g., [3][4]) and many other researchers are claiming that RBV says that competitive advantage of companies depends on the features of resources that companies possess and on the application of those resources. In case of applying this assertion of researchers in colleges, it means that competitiveness can be possessed depending on how the features of resources those colleges own and how they are applied. In this view, core competence of community colleges is a very significant factor.

The core competence that [5] proposed can be seen as a main feature to strategically operate in RBV. core competence generally means the core competence of organizations and this means the resources and competence required by organizations to create core value such as company interior manpower - technology - knowledge $\cdot$ culture. This does not simply mean activity that an organization is good at, but means outstanding activity that allows maintenance of competitive advantage with competitive companies [2][6]'s core competence of companies is representative researches related to core competence in which they defined core competence as 'ability of particular method to increase value to customers or make the process of delivering that value more efficiently in which this ability can allow companies to advance to new industry.'

[7] defined collective-efficacy as the belief of group ability of organization members and colleagues in the process of solving problems that occur during work. Meanwhile, [8] defined it as perception of the degree possibility of outcome a group can reach. In this aspect, collective-efficacy of enrolling students on community college members and collectiveefficacy of department members has high possibility to enhance self-efficacy and self-esteem of enrolling students. Thus, high level collective-efficacy can be a significant actor to increase satisfaction or loyalty of an associated group. Therefore, it was defined in this study that collective-efficacy is personal belief on the competence of community colleges and departments.

[7] said that self-efficacy is a dynamic form derived from the concept of social cognitive theory and is an interactive model receiving influence from behavior, awareness, and environment. According to his assertion, success and failure of past work is assessed and goal, behavior plans are made by self-efficacy. Individual motive, thought pattern, behavior is mediated by self-efficacy and individual thoughts and behavior are influence. The reason selfefficacy of enrolling of students is noticed as a significant factor is because first, as [7] asserts, people who think ability is gainable have higher self-efficacy than those who do not and people who have high self-efficacy put more effort although that ability is not easily gained.

Self-esteem means the degree of how much something is important to someone and means subjective assessment on how much one likes, accepts, respects oneself and how much one thinks oneself is a valuable human being (e.g., [9]) [10] defined self-esteem as an important factor of forming human behavior, social adaptation, and sound personality with the value judgment one has on oneself. [11] defined it as evaluative attitude one has depending on satisfaction of conducting a role. Self-esteem can be understood through social identity theory. Based on the definition by [13], self-esteem was defined as an attitude on oneself respecting and considering oneself valuable in this study.

Satisfaction can be defined as a psychological status that members have depending on aspect or degree of personal attitude, value, belief or desire [14]. This gives significant 
influence of results, attitude, and behavior of members and this influence is ultimately connected to the goal achievement of organizations [15]. When applying this in college, satisfaction of department can be defined as a psychological status of enrolling students depending on the aspect or degree of personal attitude, value, belief or desire associated to the department. Therefore, whether enrolling students are satisfied with their department can be applied as an important variable related to the strengthening of competitiveness of that department. Therefore, satisfaction of department was defined as the positive psychological status that a community college student has on the associated department in this study.

\section{Research model and hypotheses}

[16] reported that characteristics of individuals and organizations are similar that if P-O fit is enhanced, satisfaction and results also increase in which stress is minimized. Also high level P-O fit increases focus on organization and maintains employees which in result increases the satisfaction of employees. Several researchers around the world (e.g [17]) have recognized this as a main tool to bring competitive advantage to companies. Thus, it could be judged that high $\mathrm{P}-\mathrm{O}$ fit is found when degree of awareness of college or department core competence had positive influence on self-efficacy and self-esteem. In this case, it means that satisfaction on department or GPA can be increased. Based on the basis of the advanced researches above, the following structured research model and hypotheses were established. There are not showed the hypothesis of mediating effect of self-efficacy and self-esteem.

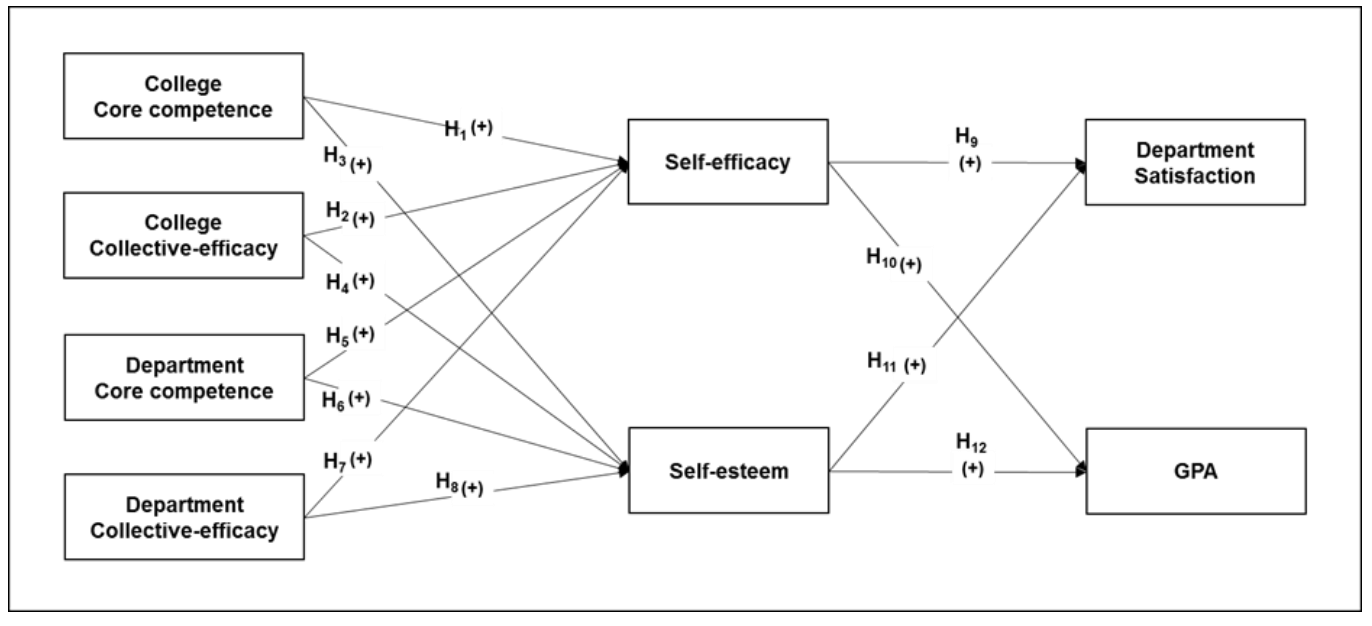

Figure 1. Research model and hypotheses

\section{Data collection and research methods}

1,052 participants of surveys were collected to A College and 847 participants $(80.5 \%)$ excluding insincere responses were used in this study. 691 participants (81.6\%) with GPA recorded by valid respondents were used in analysis. Looking into the demographic features of respondents, the following results were shown. First there were slightly more female students $380(55.6 \%)$ than male students $303(44.4 \%)$ Due to the property of community colleges, age ranges showed the most 318 respondents (46.4\%) between 20 22 years old, 186 respondents of 22 years old and older (27.1\%), and 182 respondents under 20 years old.

9 items based on [6]'s research were given for core competence of college and department, 7 items based on [18]'s research were given for collective-efficacy on school and department, 
and 3 items related to satisfaction in the outcome analysis index of the Ministry of Knowledge Economy for satisfaction of department were given in which each items were measured by the Likert 7-point scale. 10 items based on [9]'s research for self-esteem were given and measured by the Likert 5-point scale and the GPA of students were to be directly written.

\section{Results}

To assess if the measured items are maintaining internal consistency, Cronbach's $\alpha$ was used and result of verifying reliability, all variables showed high values of $0.877 \sim 0.928$ compared of the value 0.7 proposed by [19] in which it was judged that reliability existed. Concept reliability was $0.809 \sim 0.927$ and all AVE except self-efficacy all showed 0.5 or higher values in which validity was obtained. In case of self-efficacy, AVE value of below 0.5 , but comparison of squared value of correlation coefficient and determination coefficient showed validity.

For verification of hypotheses, sex, age, and department among demographic variables were controlled for regression analysis. As result, college core competence $(\beta=0.291, \mathrm{p}<.01)$ and college collective-efficacy $(\beta=0.352, \mathrm{p}<.01)$ on self-efficacy both showed statistically significant positive influence. College core competence $(\beta=0.205, \mathrm{p}<.01)$ and college collective-efficacy $(\beta=0.180, \mathrm{p}<.01)$ on self-esteem both showed statistically significant positive influence. Therefore, hypothesis $1,2,3$ and hypothesis 4 was adopted, respectively.

Department core competence $(\beta=0.343, \mathrm{p}<.01)$ and department collective-efficacy $(\beta=$ $0.414, \mathrm{p}<.01)$ on self-efficacy both showed statistically significant positive influence, and department core competence $(\beta=0.180, \mathrm{p}<.01)$ and department collective-efficacy $(\beta=$ $0.231, \mathrm{p}<.01)$ on self-esteem also both showed statistically significant positive influence. Therefore, hypothesis 5, 6, 7 and hypothesis 8 was also adopted, respectively.

Self-efficacy of enrolling students showed statistically significant positive influence on satisfaction of department $(\beta=0.314, \mathrm{p}<.01)$ and on GPA $(\beta=0.151, \mathrm{p}<.01)$ Self-esteem had positive influence on satisfaction of department $(\beta=0.314, \mathrm{p}<.01)$, but GPA $(\beta=-.016, n . s)$ did not statistically significance in which hypothesis 9,10 and hypothesis 11 was adopted, respectively. However, hypothesis 12 was not adopted.

In result of verifying mediating effect of self-efficacy and self-esteem by the three-step mediated regression analysis of [20], it was shown that only self-efficacy partially mediated college core competence with satisfaction of department, and department core competence with satisfaction of department.

\section{Conclusions}

The conclusion and implications achieved through analysis are as follow. First as result of verification of direct effect, it was confirmed that not only core competence of college and collective-efficacy, but also core competence and collective-efficacy of department also have positive influence in increasing self-efficacy and self-esteem of enrolling students. This result implies that colleges and departments must not spare effort to strengthen core competence. For this, colleges and departments must first diagnose which competence they have and must check the pros and cons according to the results. They must be improved and strategic approach is required to use opportunities of current situations and correspond to threats. Specially to strengthen core competence, the formative principle of self-esteem that [20][9] and [21] asserted as factors to enhance self-efficacy must be reflected in building and 
delivering core competence of colleges and departments to gain substantial effect. Selfefficacy can be inspired through experience of achievement, substitution learning, linguistic persuasion, and emotional excitement [20]. Self-esteem can be increased through assessment reflected by others, social comparison, and self-serving [9], [21]. Therefore, it means that colleges and departments must find and develop core competence to promote these factors to members. Also, it as shown that self-efficacy has positive effect on satisfaction of department and GPA. In case of self-esteem, positive influence was shown on satisfaction of department, but it could be known that there was no influence on GPA. These results must be able to be recognized by enrolling students themselves and measurements for outsiders or the media to have positive comparison are required.

Second, mediation effect analysis results in aspect of P-O fit had somewhat different results from above. Specifically, self-efficacy showed to partially mediate college core competence, college collective-efficacy with satisfaction of department, and department core competence with satisfaction of department. However, it was confirmed that self-efficacy and self-esteem had no mediation effect between independent variables and GPA, and it was also known that there was no mediation effect between self-esteem and satisfaction of department. Especially in case of self-esteem, it is implied that consideration on incoming resources to community colleges is needed. Applying the social identity theory that people cannot live alone and receive interaction as a member in various groups in which the group value is internalized to oneself, it can be seen that community college students have low degree of value awareness of themselves and that the sense of belonging to college does not have positive influence on emotions or feelings. Therefore, community colleges must actively have informed various negative information in the eye-level of enrolling students and finding understanding on this can be a strategy.

\section{References}

[1] Y.C. Lee, S.J. Park, M.S. Kim, and C.S, Lee, “College self-assessment study on the development," Korea College Education Council, (2013)

[2] T.W. Lee, "An empirical study on the effect of value innovation strategy and core competence on business performance," PhD Thesis of Kyonggi University, (2011)

[3] A. M. Rugman and A. Verbeke, Strategic Management Journal, vol.23, no.8, (2002)

[4] R. P. Rumelt, "Competitive strategic management," vol.26

[5] R. Penrose, Editor, "The theory of the growth of the firm," London: Blackwell. Republished in 1980. NY: Sharpe, White Plains

[6] C. K. Prahalad and G. Hamel, Editor, "The core competence of the corporation," MA: Boston

[7] A. Bandura, Editor, "Social learning theory," Englewood Cliffs

[8] D.J. Mesch, J.L. Farth, and P.M. Podsakoff, "Group organizational management," vol.19, no.3

[9] M. Rosenberg, Editor, "Society and adolescent self-image," Princeton, NJ: Princeton University

[10] C. R. Rogers, Editor, "Client-centered therapy: its current practice, implications, and theory," Boston: Houghton Mifflin

[11] J. A. Beane and R. P. Lipka, Editor, "Self-concept, self-esteem and the curriculum," Boston, MA: Allyn and Bacon

[12] L.E. Atwater and F. J. Yammarino, "Personnel psychology," vol.45, no.1

[13] R. W. Betty and C. E. Schnier, Editor, "Personal administration: an experimental skill building approach $\left(2^{\text {nd }}\right)$," New York: Addison-Wesly Publishing Company

[14] E. A. Locke, Editor, "The nature and causes of job satisfaction," In M. D. Dunnette (Ed.), Handbook of Industrial and Organizational Psychology, pp.1297-1343, Chicago: Rand McNally 
The Effects of Students Cognition of Their College and Departments Core Competencies and

Collective-efficacy on Satisfaction and GPA

[15] M. Mount and P. Muchinsky, J. Vocational Behavior, vol.13

[16] R. T. Mowday, R. M. and L. W. Porter, J. Vocational Behavior, vol.14

[17] M. L. Riggs and P. A. Knight, J. Applied Psychology, vol.79, no.5

[18] J. C. Nunnally, Editor, "Introduction to psychological measurement," New York: McGraw-Hill

[19] R. M. Baron and D. A. Kenny, J. Personality and Social Psychology, vol.51

[20] G. E. Prussia and A. J. Kinicki, J. Applied Psychology, vol.81, no.2 